\title{
Calibration of a Platinum Resistance Thermometer (Pt-100) and Its Measurement Uncertainty Analysis
}

\author{
Levent Paral ${ }^{1 *}$, Faruk Durmaz ${ }^{2}$, Olcay Aydın ${ }^{1}$ \\ ${ }^{1 *}$ Departments of Electronics and Automation, Manisa Celal Bayar University, \\ Turgutlu, Manisa, Turkey, +90 2363135502 \\ levent.parali@cbu.edu.tr; olcay.aydin@cbu.edu.tr \\ ${ }^{2}$ Department of Computer Programming, Manisa Celal Bayar University, \\ Turgutlu, Manisa, Turkey, +90 2363135502 \\ faruk.durmaz@cbu.edu.tr \\ *Corresponding author
}

Received: 16 August 2017

Accepted: 5 March 2018

DOI: $10.18466 /$ cbayarfbe. 334988

\begin{abstract}
A common problem found in the industrial metrology is the reliability of the results obtained from temperature instruments, especially when they are used in operational processes which effect to the production quality. In this case, calibration of thermometer associated with a national standard through a documented unbroken chain of calibrations is of vital importance. This study presents the reliability of a Pt-100 Platinum Resistance Thermometer (PRT) measurement results which can be described according to calibration and statistical methods. The calibrated PRT's resistance values are characterized as around $131.00 \Omega$ by making a comparison with a reference PRT at $80{ }^{\circ} \mathrm{C}$ bath temperature and the total uncertainty of the calibration temperature is determined as $\pm 0.08656{ }^{\circ} \mathrm{C}$ by metrological traceability together with measurement uncertainty. The total uncertainty value changes depending on uncertainty values of each equipment used in the calibration system.
\end{abstract}

Keywords - Platinum resistance thermometer, Metrology, Calibration measurement system, Uncertainty.

\section{Introduction}

Metrology is defined by the International Bureau of Weights and Measures (BIPM: Bureau International des Poids et Mesures) as the science of measurement, including both experimental and theoretical determinations at any level of uncertainty in any field of science and technology. Metrology is separated into three categories such as scientific metrology, industrial metrology, and legal metrology. Scientific metrology covers the organization and development standard, and their maintenance. Legal metrology originated from the need to ensure fair trade, especially in the area of weights and measures while industrial metrology has to guarantee the adequate functioning of measurement devices used in industrial production and in the testing process $[1,2]$.

In science and engineering, objects of interest have to be characterized by measurement and testing. Measurement is the assignment of a value to a characteristic of an object or event, which can be compared with other objects or events. Calibration consists of comparing the output of instrument or sensor under test against the output of an instrument of known accuracy when the same input as the measured quantity is applied to both instruments. Instrument calibrations have to be repeated at prescribed intervals because of the characteristics of any instrument change over period. Changes in the instrument characteristics are brought some factors such as mechanical wear, dirt, dust, temperature changes in the operating system [3].

Measurements in the calibration can be related to a national standard through a documented unbroken chain of calibrations. The primary standards in the calibration laboratories such as National Physical Laboratory are used to calibrate reference (secondary) standards held by accredited calibration laboratories. These reference standards are used to calibrate working standards that may be company master standards in the industry, hospitals. Reference and working standards can be used measuring instruments such as multimeters, voltmeter, thermometer, weight meter, etc. Usually national or international standards, through an unbroken chain of comparisons, all having stated uncertainties. The level of traceability establishes the level of comparability of the measurement: whether the result of a measurement can be compared to 
the previous one, a measurement result a year ago, or to the result of a measurement performed anywhere else in the world [4]. Measurement is carried out by making a comparison between a target objective and a measurand that is a quantity intended to be measured. Measured quantity values are obtained as measurement results. In the calibration, a measurement result can be expressed by metrological traceability together with measurement uncertainty, the reliability of the measurement result can be reasonably confirmed and maintained. Uncertainty is the range of doubt surrounding a measured or calculated value within which the true value is expected to fall with some degree of confidence. The uncertainty value should be expressed with an associated statistical confidence. [5, $6,7]$

The resistance type thermometer is specially designed for heavy-duty temperature sensing applications like ovens, machines, and industrial environments where their durable construction ensures a prolonged sensor. The sensor of a resistance thermometer features a temperaturedependent electrical resistance. This increases with the temperature and is therefore known as a PTC (positive temperature coefficient). With industrial measuring requirements, primarily Pt-100 or Pt-1000 measuring resistors are used to EN60751 and available in accordance with IEC 751.

This study aims how to express the reliability of Pt-100 Platinum Resistance Thermometer (PRT) calibration measurement results which can be described according to calibration and statistical methods.

\section{Materials and Methods}

In this study, the PRT with known parameters (See
Table.1) is used under calibration readout system. The calibration characterizations of the PRT are measured at room temperature employing a readout system with bath which is controlled by a digital control system with a software.

\subsection{Pt-100 Platinum Resistance Thermometer (PRT)}

A PRT is a device which determines the temperature by measuring the electrical resistance of a piece of pure platinum wire. The piece of platinum wire referred to as a temperature sensor. If these PRTs are manufactured carefully, they offer an excellent combination of sensitivity, range, and reproducibility.

The electrical resistance metal of many metals such as copper, silver, aluminum, platinum increase approximately linearly with absolute temperature and this feature provides them useful as temperature sensors. The resistance of wire of the material is measured by passing a current (AC or DC) through it and measuring the voltage with suitable bridge or voltmeter, and reading is converted to temperature using calibration equation. [8]

The length and diameter of the platinum wire used in a thermometer are often chosen so that the resistance of the device at around $0{ }^{\circ} \mathrm{C}$ is $100 \mathrm{ohm}$. Such a sensor is called a Pt-100 sensor, its resistance changes by approximately 0.4 ohms per degree Celcius. In other words, using a typical $1 \mathrm{~mA}$ measuring current at $0{ }^{\circ} \mathrm{C}$, a PTR would have a voltage drop of about $100 \mathrm{mV}$ across its terminals and this would change by about $0.4 \mathrm{mV}$ per degree Celsius. Therefore, it makes sensitive thermometry available to anyone with a high-resolution voltmeter or resistance bridge. PRT (Pt-100) conversion table is indicated in Table 1.

Table 1. PRT (Pt-100) Conversions $-70^{\circ} \mathrm{C}$ to $99^{\circ} \mathrm{C}$, Temperature Coefficent -0.00385 Ohms $/ \mathrm{Ohm} /{ }^{\circ} \mathrm{C}$.

\begin{tabular}{|c|c|c|c|c|c|c|c|c|c|}
\hline${ }^{\mathbf{0}} \mathbf{C}$ & $\mathbf{\Omega}$ & ${ }^{\mathbf{0}} \mathbf{C}$ & $\boldsymbol{\Omega}$ & ${ }^{\mathbf{0}} \mathbf{C}$ & $\boldsymbol{\Omega}$ & ${ }^{\mathbf{0}} \mathbf{C}$ & $\boldsymbol{\Omega}$ & ${ }^{\mathbf{0}} \mathbf{C}$ & $\boldsymbol{\Omega}$ \\
\hline-70 & 72.33 & -36 & 85.85 & -2 & 99.22 & 32 & 112.45 & 66 & 125.54 \\
\hline-69 & 72.73 & -35 & 86.25 & -1 & 99.61 & 33 & 112.83 & 67 & 125.92 \\
\hline-68 & 73.13 & -34 & 86.64 & $\mathbf{0}$ & $\mathbf{1 0 0 . 0 0}$ & 34 & 113.22 & 68 & 126.31 \\
\hline-67 & 73.53 & -33 & 87.04 & 1 & 100.39 & 35 & 113.61 & 69 & 126.69 \\
\hline-66 & 73.93 & -32 & 87.43 & 2 & 100.78 & 36 & 113.99 & 70 & 127.07 \\
\hline-65 & 74.33 & -31 & 87.83 & 3 & 101.17 & 37 & 114.35 & 71 & 127.45 \\
\hline-64 & 74.73 & -30 & 88.22 & 4 & 101.56 & 38 & 114.77 & 72 & 127.84 \\
\hline-63 & 75.13 & -29 & 88.62 & 5 & 101.95 & 39 & 115.15 & 73 & 128.22 \\
\hline-62 & 75.53 & -28 & 89.01 & 6 & 102.34 & 40 & 115.54 & 74 & 128.60 \\
\hline-61 & 75.93 & -27 & 89.40 & 7 & 102.73 & 41 & 115.93 & 75 & 128.98 \\
\hline-60 & 76.33 & -26 & 89.90 & 8 & 103.12 & 42 & 116.31 & 76 & 129.37 \\
\hline-59 & 76.73 & -25 & 90.19 & 9 & 103.51 & 43 & 116.70 & 77 & 129.75 \\
\hline-58 & 77.13 & -24 & 90.59 & 10 & 103.90 & 44 & 117.08 & 78 & 130.13 \\
\hline-57 & 77.52 & -23 & 90.98 & 11 & 104.29 & 45 & 117.47 & 79 & 130.51 \\
\hline-56 & 77.92 & -22 & 91.37 & 12 & 104.68 & 46 & 117.85 & $\mathbf{8 0}$ & $\mathbf{1 3 0 . 9 0}$ \\
\hline-55 & 78.32 & -21 & 91.77 & 13 & 105.07 & 47 & 118.24 & 81 & 131.28 \\
\hline-54 & 78.72 & -20 & 92.16 & 14 & 105.46 & 48 & 118.62 & 82 & 131.67 \\
\hline
\end{tabular}




\begin{tabular}{|l|l|l|l|l|l|l|l|l|l|}
\hline-53 & 79.11 & -19 & 92.55 & 15 & 105.85 & 49 & 119.01 & 83 & 132.05 \\
\hline-52 & 79.51 & -18 & 92.95 & 16 & 106.24 & 50 & 119.40 & 84 & 132.43 \\
\hline-51 & 79.91 & -17 & 93.34 & 17 & 106.63 & 51 & 119.78 & 85 & 132.80 \\
\hline-50 & 80.31 & -16 & 93.73 & 18 & 107.02 & 52 & 120.16 & 86 & 133.18 \\
\hline-49 & 80.70 & -15 & 94.12 & 19 & 107.40 & 53 & 120.55 & 87 & 133.56 \\
\hline-48 & 81.10 & -14 & 94.52 & 20 & 107.79 & 54 & 120.93 & 88 & 133.94 \\
\hline-47 & 81.50 & -13 & 94.91 & 21 & 108.18 & 55 & 121.32 & 89 & 134.32 \\
\hline-46 & 81.89 & -12 & 95.30 & 22 & 108.57 & 56 & 121.70 & 90 & 134.70 \\
\hline-45 & 82.29 & -11 & 95.69 & 23 & 108.96 & 57 & 122.09 & 91 & 135.05 \\
\hline-44 & 82.69 & -10 & 96.09 & 24 & 109.35 & 58 & 122.47 & 92 & 135.46 \\
\hline-43 & 83.08 & -9 & 96.48 & 25 & 109.73 & 59 & 122.86 & 93 & 135.84 \\
\hline-42 & 83.48 & -8 & 96.87 & 26 & 110.12 & 60 & 123.24 & 94 & 136.22 \\
\hline-41 & 83.88 & -7 & 97.26 & 27 & 110.51 & 61 & 123.62 & 95 & 136.60 \\
\hline-40 & 84.27 & -6 & 97.65 & 28 & 110.90 & 62 & 124.01 & 96 & 136.98 \\
\hline-39 & 84.67 & -5 & 98.04 & 29 & 111.28 & 63 & 124.39 & 97 & 137.36 \\
\hline-38 & 85.06 & -4 & 98.44 & 30 & 111.67 & 64 & 124.77 & 98 & 137.74 \\
\hline-37 & 85.46 & -3 & 98.83 & 31 & 112.06 & 65 & 125.16 & 99 & 138.12 \\
\hline
\end{tabular}

PRTs are named as depending on the element type Pt-100, Pt-200, Pt-500 or Pt-1000, and they are an excellent choice for use as cryogenic temperature sensing and control elements in the range from $30 \mathrm{~K}$ to $873 \mathrm{~K}\left(-243{ }^{\circ} \mathrm{C}\right.$ to $\left.600{ }^{\circ} \mathrm{C}\right)$. Over this temperature span, PRTs offer high repeatability and nearly constant sensitivity, dR/dT. Platinum resistors are also of use as control elements in magnetic field environments where errors approaching a degree can be tolerated. It is shown that a Pt-100 resistance thermometer in Figure 1.

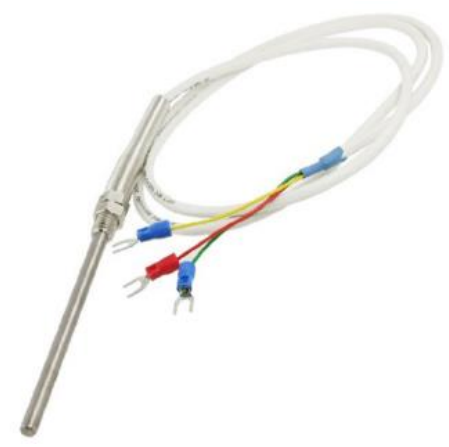

Figure 1. Pt-100 Resistance Thermometer.

\subsection{Preparing the PRT for Calibration}

All temperature sources have instabilities and gradients. These translate into calibration errors or uncertainties. To decrease the effects, the probes should be placed as close together as practical applications. In baths, the probes to be calibrated should be placed in a radial pattern with the reference probe in the center (focus) of the circle. This ensures an equal distance from the reference probe to each of the probes under tests.

Also, the sensing elements should be on the same horizontal plane. Even though sensing elements are different lengths, having the bottoms of the probes at the same level is sufficient. Sufficient immersion must be achieved so that stem losses do not occur.

Generally, sufficient immersion is achieved when the probes are immersed to a depth equal to 20 times the probe diameter plus the length of the sensing element. For example, consider a 3/16 inch diameter probe with a 1 inch long sensing element. Using the rule of thumb, $20 \mathrm{x}$ $3 / 16$ in +1 in $=33 / 4$ in +1 in $=43 / 4$ in. In this example, minimum immersion is achieved at $43 / 4$ inches. If the probe has thick wall construction and/or poor heat transfer is present (such as in the case of a dry-well with incorrectly sized holes), more immersion is required. [9]

\section{Calibration Readout System}

There are two types of calibrations applicable to PRT as characterization or tolerance testing. Characterization is the type of calibration type where the calibrated PRT resistance under test is determined at several temperature points and data are fitted to mathematical expression. Also, tolerance testing is a calibration in which the PRT resistance is compared to define values at the specific temperature. In the laboratory, we have to perform both types of calibration depending on our customer's needs.

Connections of the Pt-100 to a readout system must be tight and in proper 2-, 3-, or 4-wire configuration. If it uses a Pt-100 which has a 4-wire configuration, the current and voltage connections are shown that Figure 2.

In this study, PRTs are calibrated with a standard reference platinum resistance thermometer in temperature-stabilized baths using fixed-points to provide reference temperatures over the ranges specified in the ITS-90 (International Temperature Scale of 1990) [10]. The reference equipment such as the platinum resistance, the resistance 
thermometer bridge (ASL F18) or the standard resistor must also have been traceably calibrated can be used.
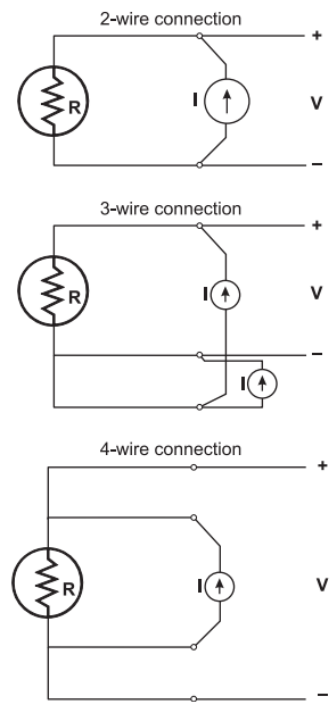

Figure 2. Thermometer readout connections.

An experimental setup of PRT Calibration Readout System is presented in Figure 3. The presented Readout system includes temperature-stabilized bath which has a temperature controller, digital multimeters that are used for reference and calibrated PRTs, GBIP-RS 232 Interfaces, and a computer.

Nowadays, to obtain more efficient calibration measurements, the scientific studies which of include both hardware and software on developments of the LabVIEW based digital system continue currently. These studies aim to demonstrate a successful comparison with commercial systems [11]. Also, the instrument of ambient temperature is fixed close to the measuring equipment.

A calibration bath cannot be considered as completely stable in time and homogeneous all over its volume, especially when temperature calibrations by comparison are carried out at the best level of uncertainty. This represents a major contribution to the total uncertainty of a calibration procedure. In order to decrease this uncertainty contribution, the equalizing blocks are used depending on the bath dimension [12].

\subsection{Temperature determinations of PRTs}

The resistance values of the reference PRT is measured and the temperature calculated from calibration coefficient which was entered into the readout previously.

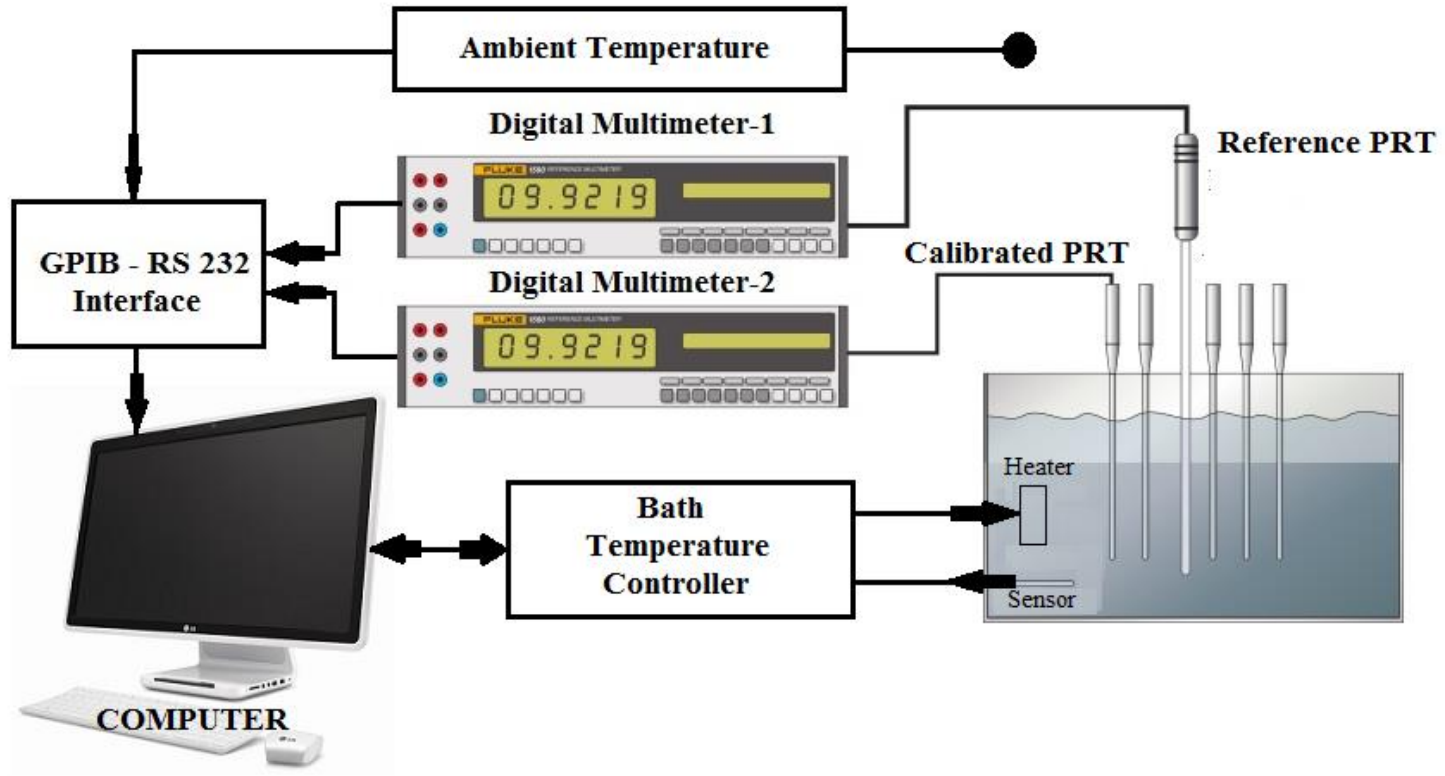

Figure 3. PRT Calibration Readout System.

These calibration coefficients have been entered, the temperature calculations are accomplished internally and readout system displays in temperature units and the temperature data are available in real time. This feature speed ups process and provides to reduce uncertainty values due to operator errors.

In this study, the digital multimeter is used to measure the resistance value of the reference PRT while it is exposed to a temperature. The reference PRT must also have been calibrated by a traceable laboratory. The resistance values of the calibrated PRT under test is measured via another digital multimeter when it is exposed to the same temperature with reference PRT.

\subsection{Calibration Procedure}

With comparison calibration method, a new resistance 
value against temperature is determined at each calibration step. Generally, with this type of calibration, new calibration coefficients and a calibration table are provided as a product of the calibration. There are five basic steps to perform as ranked below:

- The reference and the calibrated PRTs were placed into the temperature-stabilized bath in close proximity to each other.

- Connections of the PRT to a readout system must be tight and in proper 2-, 3-, or 4-wire configuration.

- The resistance value of the reference PRT was measured and its temperature value was determined.

- The resistance value of the calibrated PRT was measured.

- The experimental data were fitted separately to a mathematical expression.

\section{Results and Discussion}

4.1 Determining the Temperature Value against Resistance Value of the Reference PRT.

Determining the calibration temperature for the reference PRT must be calculated by using interpolation which is given at ITS-90 after the resistance value of the reference PRT is measured at $80{ }^{\circ} \mathrm{C}$ by following the example.

Table 2. Interpolation from the reference PRT calibration (temperature vs resistance)

\begin{tabular}{|c|c|c|}
\hline $\mathbf{T}\left({ }^{\circ} \mathbf{C}\right)$ & $\mathbf{R}(\mathbf{t})(\mathbf{\Omega})$ & $\mathbf{d R} / \mathbf{d t}(\mathbf{t}) \mathbf{\Omega} /{ }^{\circ} \mathbf{C}$ \\
\hline 80 & 130.9020 & 0.3815 \\
\hline 81 & 131.2835 & 0.3814 \\
\hline 82 & 131.6748 & 0.3813 \\
\hline 83 & 132.0560 & 0.3812 \\
\hline 84 & 132.4318 & 0.3811 \\
\hline
\end{tabular}

Measure the reference PRT resistance at $80{ }^{\circ} \mathrm{C}: 130.9252$ $\Omega$.

Locate where it falls on Table 2 : between 130.9020 and $131.2835 \Omega$.

Substract lower table value from measured value: $130.9252 \Omega-130.9020 \Omega=0.0232 \Omega$.

Divide by $\mathrm{dR} / \mathrm{dt}(\mathrm{t})$ (slope of curve): $0.0232 / 0.3815=0.0608^{\circ} \mathrm{C}$

Add fractional temperature to table value: $\mathrm{T}_{\mathrm{r}}=80{ }^{\circ} \mathrm{C}+0.0608^{\circ} \mathrm{C}=\mathbf{8 0 . 0 6 0 8}^{\circ} \mathrm{C}$

The temperature of the calibrated PRT can be determined by measurements concerned with reference PRT and defining some additional corrections. [12]

$$
T_{c}=T_{r}+\delta T_{a c q T r}+\delta T_{a c q T c}+\delta T_{B a t h}+\ldots \ldots
$$

Where,

$\mathrm{T}_{\mathrm{c}}$ : Temperature of the calibrated PRT.

$\mathrm{T}_{\mathrm{r}}$ : Temperature of the reference PRT

$\mathrm{T}_{\mathrm{acqTr}}$ : Correction linked with multimeter of the reference PRT.

$\mathrm{T}_{\text {acqTc }}$ : Correction linked with multimeter of the calibrated PRT.

$\mathrm{T}_{\text {Bath: }}$ Correction linked with the bath which has some properties such as homogeneity, stability.

\subsection{Determining the Resistance Value of the Calibrated PRT}

The resistance of the calibrated PRT is measured at $80{ }^{\circ} \mathrm{C}$ by using a multimeter, first. After that, the resistance value of calibrated PRT is determined by the following equation $[13,14]$ :

$$
R_{c}(t)=R_{c}+\delta R_{c l}+\delta R_{c 2}+\delta R_{c 3}+\delta R_{c 4}+\ldots
$$

Where,

$\mathrm{R}_{\mathrm{c}}$ : The calibrated PRT resistance value that the multimeter reads,

$\mathrm{R}_{\mathrm{c} 1}$ : Correction linked with multimeter calibration,

$\mathrm{R}_{\mathrm{c} 2}$ : Correction linked with multimeter time stability,

$\mathrm{R}_{\mathrm{c} 3}$ : Correction linked with multimeter resolution,

$\mathrm{R}_{\mathrm{c} 4}$ : Correction linked with connections,
$\mathrm{R}_{\mathrm{c}}(\mathrm{t})=130.9871 \Omega+0.01 \Omega+0.5 \mathrm{~m} \Omega+0.29 \mathrm{~m} \Omega+0 \Omega$ $\mathrm{R}_{\mathrm{c}}(\mathrm{t})=\approx 131.00 \Omega$.

Uncertainties linked with 2 multimeters which used for data acquisition of the reference and the calibrated PRTs are ranked as follow: [13]

$\boldsymbol{U}_{\boldsymbol{R} o h m}, \boldsymbol{U}_{\text {Cohm }}$ : Type-uncertainty due to the multimeters are used for PRTs. The measurement uncertainty of the multimeters is obtained as $0.010 \Omega$ according to its calibration certificate.

$\boldsymbol{U}_{\boldsymbol{R} s t}, \boldsymbol{U}_{\boldsymbol{C} s t}$ : Type-uncertainty owing to time stability of the multimeters in accordance with their user manual. This uncertainty value is defined as $0.0005 \Omega$.

$\boldsymbol{U}_{\boldsymbol{R} a m b}, \boldsymbol{U}_{\text {Camb }}$ : Type-uncertainty due to ambient temperature influence. Within prescribed temperature interval the component is neglected. $(0 \Omega)$.

$\boldsymbol{U}_{\text {Rres, }}, \boldsymbol{U}_{\text {Cres }}$ : Type-uncertainty due to the multimeter's resolution according to least significant bit (LSB). The limited resolution of the multimeter is within $\pm 0.0005 \Omega$ for $0,001 \Omega$. Therefore, the standard uncertainty of the multimeter is defined as $0.0005 \Omega / \sqrt{3}=0.29 \mathrm{~m} \Omega$. 
$\boldsymbol{U}_{\boldsymbol{R} m u x}, \boldsymbol{U}_{\text {Cmux }}$ : If the multiplexer device is used at calibration read out system, its noise factor value must be attached to the total uncertainty values. Since the multiplexer device is not used, it can be neglected $(0 \Omega)$.

$\boldsymbol{U}_{\boldsymbol{R} \text { con, }} \boldsymbol{U}_{\text {Ccon: }}$ Since the calibrated PRT which has a 4-wire configuration is connected to the multimeter and the uncertainty associated with this connection type is taken to be neglected $(0 \Omega)$.

\subsection{Identification of Uncertainties}

The temperature uncertainties on calibration activity are sorted as the following [13]:

\subsubsection{Uncertainties linked with Reference PRT}

$\boldsymbol{U}_{T r r}$ : It is repeatability of measurements that refers to the variation in repeat measurements made on the same subject under identical conditions. This means that measurements are made by the same instrument or method, the same observer (or rater) if a human input is required and that the measurements are made over a short period of time, over which the underlying value can be considered to be constant. [15]

The repeatability of measurements of the reference PRT is performed totally 10 times measuring a value every 30 seconds, separately.

The complete process of calculating the estimated standard deviation for a series of $\mathrm{n}$ measurements can be expressed mathematically as:

$$
s=\sqrt{\frac{\sum_{i=1}^{n}\left(x_{i}-\bar{x}\right)^{2}}{(n-1)}},
$$

Standard deviation of the measurement average is calculated as $\boldsymbol{U}_{\boldsymbol{T r} r}=0.002{ }^{\circ} \mathrm{C}$.

$\boldsymbol{U}_{\text {Trc }}$ : It is the standard uncertainty of the reference PRT. The calibration certificate of the reference PRT contains information about some corrections. For this study, standard uncertainty is determined as $0.01{ }^{\circ} \mathrm{C}$.

$\boldsymbol{U}_{\text {Trd }}$ : It is estimated from the maximum drift over all the drift values between successive calibrations. When the instrument is a new one, the manufacturer's data is taken into account to obtain stability at uncertainty budget calculations. If the instrument is the older one and no manufacturer's data is available, the drift can be estimated as standard uncertainty in the calibration of reference PRT.

In this study, the drift between calibrations is $0.01{ }^{\circ} \mathrm{C}$.

$$
u_{T r d}=\frac{0.01}{\sqrt{3}}=0.0058^{\circ} \mathrm{C}
$$

$\boldsymbol{U}_{\text {Trcon: }}$ Type-uncertainty due to a possible heat conduction by the reference PRT. Measurements obtained PRTs should be made at different immersion depths. Removing the reference standard $20 \mathrm{~mm}$ out the bath leads to a temperature change of $0.002^{\circ} \mathrm{C}$. Therefore, it is calculated as $0.0012^{\circ} \mathrm{C}$ due to the temperature variations of the bath.

$$
u_{\text {Trcon }}=\frac{0.002}{\sqrt{3}}=0.0012^{\circ} \mathrm{C}
$$

$\boldsymbol{U}_{\text {Trsh: }}$ Type-uncertainty due for self-heating of the reference PRT. Obtained resistance measurement by passing current through multimeter causes heating of the resistor. The resistance measurement via current leads to the self-heating of the PRT. Since the self-heating effect of the reference PRT is dependent not only on the magnitude of the current but also on the measurement conditions, for this study this effect is neglected.

$U_{\text {Trint: }}$ It is uncertainty value owing to interpolation function (ITS-90). This value is defined as $0.01^{\circ} \mathrm{C}$

\subsubsection{Uncertainties linked with Calibrated PRT}

$\boldsymbol{U}_{T c r}$ : It is the repeatability of the calibrated PRT measurements during a calibration. The repeatability of measurements of the calibrated PRT is performed totally 10 times measuring a value every 30 seconds, separately. Standard deviation of mean is calculated as $0.002{ }^{\circ} \mathrm{C}$.

$\boldsymbol{U}_{\text {Tccon: }}$ Type-uncertainty due to a possible heat conduction by the calibrated PRT under calibration. Tests should be made at different immersion depths.

$$
u_{T c c o n}=\frac{0.002}{\sqrt{3}}=0.0012^{\circ} \mathrm{C}
$$

$\boldsymbol{U}_{\text {Tchys }}$ : Type-uncertainty owing to hysteresis, and the thermal hysteresis of the calibrated PRT express as a difference in resistance at a given temperature based on the thermal history that was exposed. The resistance of the PRT will be different when the temperature is reached from an increasing direction to a decreasing direction. The magnitude of the difference will also depend on the magnitude of the temperature excursion and the design of the PRT.

This uncertainty value is obtained as $0.002{ }^{\circ} \mathrm{C}$ using manufacturer catalog.

$\boldsymbol{U}_{\text {Bath-h: }}$ It is a bath homogeneity gradient which observed 
as a change of a thermometer reading according to a change of its position inside a calibration bath. Basic gradients which can be observed are an axial and radial gradient, and uncertainty contribution of theirs is determined as the maximum temperature difference between axial and radial direction. $\boldsymbol{U}_{\text {Bath } \boldsymbol{h}}=0.0190$

$\boldsymbol{U}_{\text {Bath-s: }}$ It is an important characteristic of a bath which is the defined short-term stability of a medium temperature. This value depends on the type of regulation and flow of medium inside the bath. Because the calibration measurements are taken within the short time interval, the short-time stability is relevant. $\boldsymbol{U}_{\text {Bath }-\mathrm{s}}=0.0035{ }^{\circ} \mathrm{C}$.

Uncertainty budget of PRTs and the calibration system are shown in Table 3. Uncertainty evaluation of multimeter measurements and the final evaluation of uncertainties in the analysis of calibration data results related to PRTs are given in Table 4. and Table 5. respectively.

Table 3. Uncertainty Budget of PRTs and the Calibration System

\begin{tabular}{|c|c|c|c|c|c|c|}
\hline Quantity & PRT type & Description & $\begin{array}{c}\text { Standart } \\
\text { Uncertainty }\end{array}$ & Distribution & $\begin{array}{l}\text { Multiplication } \\
\text { Coefficient }\end{array}$ & $\begin{array}{l}\text { Uncertainty } \\
\text { Contribution }\end{array}$ \\
\hline$U_{T r r}$ & Reference & Stand. Deviation & $0.002{ }^{\circ} \mathrm{C}$ & Normal & 1 & $0.002{ }^{\circ} \mathrm{C}$ \\
\hline$U_{T r c}$ & Reference & $\begin{array}{l}\text { PRT Calib. } \\
\text { Certificate }\end{array}$ & $0.01{ }^{\circ} \mathrm{C}$ & Normal & 1 & $0.01{ }^{\circ} \mathrm{C}$ \\
\hline$U_{\text {Trd }}$ & Reference & Drift & $0.0058^{\circ} \mathrm{C}$ & Rectangular & 1 & $0.0058^{\circ} \mathrm{C}$ \\
\hline$U_{\text {Trcon }}$ & Reference & Heat Conduction & $0.0012^{\circ} \mathrm{C}$ & Rectangular & 1 & $0.0012^{\circ} \mathrm{C}$ \\
\hline$U_{T r s h}$ & Reference & Self Heating & Neglected & & & 0 \\
\hline$U_{\text {Trint }}$ & Reference & Interpolation & $0.01{ }^{\circ} \mathrm{C}$ & Normal & 1 & $0.01{ }^{\circ} \mathrm{C}$ \\
\hline$U_{\text {Rohm }}$ & Reference & $\begin{array}{l}\text { Multimeter Calib. } \\
\text { Certificate }\end{array}$ & $0.01 \Omega$ & Normal & $* 2.5$ & $0.025^{\circ} \mathrm{C}$ \\
\hline$U_{R s t}$ & Reference & $\begin{array}{l}\text { Multimeter Time } \\
\text { Stability }\end{array}$ & $0.0005 \Omega$ & Rectangular & $* 2.5$ & $0.00125^{\circ} \mathrm{C}$ \\
\hline$U_{\text {Ramb }}$ & Reference & $\begin{array}{c}\text { Ambient } \\
\text { Temperature }\end{array}$ & Neglected & - & - & 0 \\
\hline$U_{\text {Rres }}$ & Reference & $\begin{array}{l}\text { Multimeter } \\
\text { Resolution }\end{array}$ & $0.00029 \Omega$ & Rectangular & $* 2.5$ & $0.000725^{\circ} \mathrm{C}$ \\
\hline$U_{\text {Rmux }}$ & Reference & Multiplexer Noise & Neglected & - & - & 0 \\
\hline$U_{\text {Rcon }}$ & Reference & Wire Connection & Neglected & - & - & 0 \\
\hline$U_{T c r}$ & Calibrated & Stand. Deviation & $0.002^{\circ} \mathrm{C}$ & Normal & 1 & $0.002{ }^{\circ} \mathrm{C}$ \\
\hline$U_{\text {Tccon }}$ & Calibrated & Heat Conduction & $0.0012^{\circ} \mathrm{C}$ & Rectangular & 1 & $0.0012^{\circ} \mathrm{C}$ \\
\hline$U_{\text {Tchys }}$ & Calibrated & Termal Hysteresis & $0.0012^{\circ} \mathrm{C}$ & Rectangular & 1 & $0.0012^{\circ} \mathrm{C}$ \\
\hline$U_{\text {Cohm }}$ & Calibrated & $\begin{array}{l}\text { Multimeter Calib. } \\
\text { Certificate }\end{array}$ & $0.01 \Omega$ & Normal & $* 2.5$ & $0.025^{\circ} \mathrm{C}$ \\
\hline$U_{C s t}$ & Calibrated & $\begin{array}{l}\text { Multimeter Time } \\
\text { Stability }\end{array}$ & $0.0005 \Omega$ & Rectangular & $* 2.5$ & $0.00125^{\circ} \mathrm{C}$ \\
\hline$U_{C a m b}$ & Calibrated & $\begin{array}{c}\text { Ambient } \\
\text { Temperature }\end{array}$ & Neglected & - & - & 0 \\
\hline$U_{\text {Cres }}$ & Calibrated & $\begin{array}{l}\text { Multimeter } \\
\text { Resolution }\end{array}$ & $0.00029 \Omega$ & Rectangular & $* 2.5$ & $0.000725^{\circ} \mathrm{C}$ \\
\hline$U_{\text {Cmux }}$ & Calibrated & Multiplexer Noise & Neglected & - & - & 0 \\
\hline$U_{\text {Rcon }}$ & Calibrated & Wire Connection & Neglected & - & - & 0 \\
\hline$U_{\text {Bath-h }}$ & PRTs & Bath Homogenity & $0.0190^{\circ} \mathrm{C}$ & Normal & 1 & $0.0190^{\circ} \mathrm{C}$ \\
\hline$U_{\text {Bath-s }}$ & PRTs & Bath Stability & $0.0035^{\circ} \mathrm{C}$ & Normal & 1 & $0.0035^{\circ} \mathrm{C}$ \\
\hline & & & \multicolumn{3}{|c|}{$\begin{array}{l}\text { Measurement Uncertainty - } \mathbf{u} \\
\text { Expanded measurement uncertainty } \mathbf{U}=* * \mathbf{k} . \mathbf{u}\end{array}$} & $\begin{array}{c}0.04328{ }^{\circ} \mathrm{C} \\
\pm 0.08656{ }^{\circ} \mathrm{C}\end{array}$ \\
\hline
\end{tabular}


Table 4. Uncertainty evaluation of multimeter measurements

\begin{tabular}{|l|l|c|c|l|c|c|}
\hline Quantity & \multicolumn{1}{|c|}{ Description } & \multicolumn{1}{|c|}{$\begin{array}{c}\text { Measurement } \\
\Omega\end{array}$} & $\begin{array}{l}\text { Standart } \\
\text { Uncertainty }\end{array}$ & Distribution & $\begin{array}{c}\text { Multip. } \\
\text { Coeff. }\end{array}$ & $\begin{array}{c}\text { Uncertainty } \\
\text { Contribution }\end{array}$ \\
\hline $\mathrm{R}_{\mathrm{c}}(\mathrm{t})$ & $\begin{array}{l}\text { Corrected resistance } \\
\text { value of the } \\
\text { calibrated PRT }\end{array}$ & $131.00 \Omega$ & $1.28 .10^{-2}$ & Normal & 1 & 0.0128 \\
\hline $\mathrm{R}_{\mathrm{c}}$ & $\begin{array}{l}\text { The resistance } \\
\text { value of the } \\
\text { calibrated PRT that } \\
\text { the multimeter } \\
\text { reads }\end{array}$ & $130.9871 \Omega$ & $2.10^{-3}$ & Rectangular & 1 & 0.002 \\
\hline$\delta \mathrm{R}_{\mathrm{c} 1}$ & $\begin{array}{l}\text { Multimeter } \\
\text { calibration }\end{array}$ & $0.01 \Omega$ & $1.10^{-2}$ & Rectangular & 1 & 0.01 \\
\hline$\delta \mathrm{R}_{\mathrm{c} 2}$ & $\begin{array}{l}\text { Multimeter time } \\
\text { stability }\end{array}$ & $0.5 \mathrm{~m} \Omega$ & $5.10^{-4}$ & Rectangular & 1 & 0.0005 \\
\hline$\delta \mathrm{R}_{\mathrm{c} 3}$ & $\begin{array}{l}\text { Multimeter } \\
\text { resolution }\end{array}$ & $0.29 \mathrm{~m} \Omega$ & $\approx 3.10^{-4}$ & Rectangular & 1 & 0.00029 \\
\hline$\delta \mathrm{R}_{\mathrm{c} 4}$ & Connections & Neglected & & & & \\
\hline
\end{tabular}

Table 5. The final evaluation of uncertainties in the analysis of calibration data results

\begin{tabular}{|c|c|c|c|c|c|}
\hline $\begin{array}{c}\text { Calibration } \\
\text { Temperature } \\
{ }^{\circ} \mathbf{C}\end{array}$ & $\begin{array}{c}\text { Stand. } \\
\text { Uncertainty of the } \\
\text { Calibration } \\
\text { Temperature }-{ }^{\circ} \mathrm{C}\end{array}$ & $\begin{array}{c}\text { The resistance } \\
\text { value of the } \\
\text { Calibrated PRT } \\
\Omega \\
\end{array}$ & $\begin{array}{c}\text { Stand.Uncertain } \\
\text { ty of the } \\
\text { Resistance } \\
\text { Value } \Omega \\
\end{array}$ & $\begin{array}{c}\text { Stand.Uncer } \\
\text { tainty of the } \\
\text { Resistance } \\
\text { Value }{ }^{\circ} \mathrm{C} \\
\end{array}$ & $\begin{array}{c}\text { Total Standart } \\
\text { Uncertatinty } \\
{ }^{\circ} \mathbf{C}\end{array}$ \\
\hline $80.0608^{\circ} \mathrm{C}$ & $0.03530{ }^{\circ} \mathrm{C}$ & $131.00 \Omega$ & $0.0128 \Omega$ & $0.025041^{\circ} \mathrm{C}$ & $\begin{array}{c}\mathbf{0 . 0 4 3 2 8}^{\circ} \mathrm{C} \\
(\mathrm{k}=2) \pm 0.08656{ }^{\circ} \mathrm{C}\end{array}$ \\
\hline
\end{tabular}

\section{Conclusion}

In this study, the calibrated PRT's resistance value is characterized by making a comparison with a reference PRT at $80{ }^{\circ} \mathrm{C}$ temperature point and its measurement result is expressed by metrological traceability together with measurement uncertainty. The presented example describes a calibration activity of the PRT for only one temperature point. Generally, thermometers should be calibrated at several temperature points. Since the PRTs are mostly used in the heavy industry, they often must be calibrated with to the reference PRTs. The temperature value in the production systems is an important parameter that affected the quality of production. Therefore, especially development of digital-based measurement system will be prevented measurement errors, reduced measurement time.

\section{Acknowledgements}

This work was supported by the Scientific Research Council of Manisa Celal Bayar University (Project No. 2012-014).

\section{References}

1. Imai, H., Expanding needs for metrological traceability and measurement uncertainty, Measurement, 2013, 46, 2942-2945.

2. Auty, F, Willams, J, Stubbins, R, Brooks, B, Weaver, A, Cunningham M, Cash M, Begineer's Guide to Measurement in
Electronic and Electrical Engineering, National Pysical Laboratory and The Institution of Engineering and Technology (IET), http://www.npl.co.uk/training (accessed 01.08.2017)

3. Morris A.S, Measurement and Instrumentation Principle, Butterworth-Heinemann, Linacre House, Jordan Hill, Oxford OX2 8DP, 2001.

4. Duvernoy, J, Dubois, A, Instruments and Observing Methods Report No. 86, Training Materials on Metrology and Calibration, World Meteorological Organization, 2006.

5. Walker, W.E, Harremoes, P, Rothmans, J, Van Der Sluijs J.P, Van Asselt, M.B.A, Janssen, P, Krayer Von Krauss, M.P, Defining Uncertainty, A Conceptual Basis for Uncertainty Management in Model-Based Decision Support, Integrated Assessment, 2003.

6. The International Bureau of Weights and Measures (BIPM), Evaluation of measurement data-Guide to the expression of uncertaintyin measurement, JCGM 100, 2008.

7. Kacker, R, Jones, A, On use of Bayesian statistics to make the guide to the expression of uncertainty in measurement consistent, Metrologia, 2003, 40 (5), 235-248.

8. Resistance Temperature Detector (RTD) - Principle of Operation, Materials, Configuration and Benefits, Sponsored by Innovative Sensor Technology, USA Division, 2014; https://www.azom.com/article.aspx?ArticleID=5573 (accessed 01.08.2017).

9. How to Calibrate an RTD or Platinum Resistance Thermometer, Application Notes, Fluke Calibration Digital Library, July-2017; (accessed http://flukecal.com/library, (accessed 01.08.2017). 
10. Preston-Thomas, H, International Temperature Scale of 1990 (ITS90), Metrologia, 1990, 27, 3-10.

11. Schlattauer, L, Paralı, L, Pechousek, J, Sabikoglu, İ, Celiktas, C, Tektas, G, Novak, P, Jancar, A, Prochazka, V, Calibration of gammaray detectors using Gaussian photopeak fitting in the multichannel spectra with LabVIEW-based digital system, European Journal of Physics, 2017, 055806, 12.

12. Bojkovski, J, Batagelj, V, Drnovšek, J, Žužek, V, Practical Limits of Measurment Uncertainties in Calibration of Standart Platinum Resistance Thermometers by Comparison, XIX IMEKO World Congress, Fundamental and Applied Metrology, 2009, Lisbon,
Portugal, pp 1581-1584.

13. Groselj, D, Example of Measurement Uncertainty Estimations Temperature, World Meteorological Organization, Commission For Instruments and Methods of Observation, 2013.

14. Bonnier, G, Uncertainty Calculating Methods at Tempareture Measurement, TUBITAK National Metrology Institute, 2017.

15. Evaluation of the Uncertainty of Measurement in Calibration, European Accreditation, Mandatory document, EA-4/02 M: 2013, The EA Laboratory Committee, 2013. 